\title{
Pattern of Sex Differences in Growth of Saudi Children and Adolescents
}

\author{
Mohammad I. El Mouzan, MD ${ }^{1}$; Abdullah S. Al Herbish, FRCP1; \\ Abdullah A. Al Salloum, MD; Peter J. Foster, PhD²; Ahmad A. Al Omar, MD; \\ Mansour M. Qurachi, MD ${ }^{4}$; and Tatjana Kecojevic, $\mathrm{MSc}^{2}$ \\ ${ }^{1}$ Department of Pediatrics, King Saud University, Riyadh, Saudi Arabia; ${ }^{2}$ School of Mathematics, The \\ University of Manchester, Manchester, United Kingdom; ${ }^{3}$ The Children's Hospital, Riyadh Medical Complex, \\ Riyadh, Saudi Arabia; and ${ }^{4}$ Department of Pediatrics, Al Yamama Hospital, Riyadh, Saudi Arabia
}

\begin{abstract}
Background: Although variations in growth between boys and girls have been reported, detailed descriptions according to age and growth parameters are not available.

Objective: The goal of this study was to determine the pattern and magnitude of differences in growth between boys and girls according to age that justify separate growth charts.

Methods: The data set was based on a cross-sectional representative sample of the Saudi population of healthy children and adolescents from birth to 19 years of age. Body measurements (length, height, weight, and head circumference) were performed according to standard recommendations; body mass index was also determined for each subject. The difference in growth between boys and girls was assessed based on $z$ scores and percentiles (5th, 50th, and 95th) of growth parameters using 2 age groups ( $0-3$ years and 2-19 years). The significance of the difference between boys and girls for any growth parameter was tested by ANCOVA.

Results: A total of 35,279 children and adolescents from birth to 19 years of age satisfied the criteria for growth measurements. There were 17,880 boys and 17,399 girls; all were Saudi nationals. The Saudi boys were generally taller and heavier than girls up to $\sim 7$ to 10 years of age. Thereafter, girls generally were taller and heavier than boys from 10 to 14-15 years of age. After that, boys again were taller and heavier. Similar variations were observed for body mass index and head circumference. The difference between boys and girls for each growth parameter was highly significant $(P<0.001)$.

Conclusions: Based on analysis of these Saudi children and adolescents, the difference in growth between boys and girls was not uniform but depended on age. However, the pattern was remarkably consistent across all growth parameters and appears to reflect the timing of maturation between boys and girls. (Gend Med. 2010;7:47-54) @ 2010 Excerpta Medica Inc.
\end{abstract}

Key words: sex difference, growth of children, Saudi Arabia. 


\section{INTRODUCTION}

Growth parameters in the form of weight-for-age, height-for-age, weight-for-height, head circumference, and body mass index (BMI) are important tools for assessing growth of children and adolescents. Sex-specific growth charts for each growth parameter are available for children and adolescents from the United States ${ }^{1,2}$ and the United Kingdom. ${ }^{3}$ In these reports, percentile tables and curves for boys and girls have been constructed separately that show different trajectories, with no discussions of sex differences to justify this approach. The Euro-Growth references for children from birth to 3 years of age provided sex-specific tabulations with more detailed sex differences. ${ }^{4}$ The new standards published in 2006 by the World Health Organization (WHO) also provided sex-specific percentiles not only for the WHO data but also for the National Center for Health Statistics (NCHS) and the Centers for Disease Control and Prevention growth charts, indicating higher percentile curves for all growth parameters in boys from birth to 60 months, with no explanation for the differences in growth patterns between boys and girls. ${ }^{5} \mathrm{~A}$ WHO growth reference for school-aged children and adolescents from 5 to 19 years of age, published in 2007, includes higher median growth parameters for boys. ${ }^{6}$ Finally, data from the Kingdom of Saudi Arabia also presented sex-specific growth charts, with only brief comments on gender variation. ${ }^{7-10}$

Given this lack of a comprehensive description of gender variation in growth, the goal of the present study was to determine the pattern and magnitude of differences in growth between boys and girls according to age. Awareness of this information will help explain the rationale for separate sex-specific growth charts and the importance of their application in practice.

\section{METHODS}

The study was ethically cleared as part of the approval process by King Abdul Aziz City for Science and Technology (Riyadh, Saudi Arabia).

The design and methods of the Saudi reference, which is the basis of this analysis of gender variations, have been reported in detail elsewhere. ${ }^{11}$ Briefly, well-established guidelines and criteria were followed in determining the sample size. ${ }^{12}$ The study sample was cross-sectional, selected using a multistage probability sampling procedure from a stratified listing based on the population census available at the time of the study. Accordingly, the sample was representative of the socioeconomic strata and consisted of a majority of children who had received mixed breast and milk formula feedings. The highest completed level of education of the head of household for the study children was university in $16.3 \%$, secondary/intermediate school in $34.6 \%$, elementary school in $26.1 \%$, and other in $3.3 \%$. Heads of households were listed as illiterate in $19.7 \%$.

A pilot study was designed to test all components of the project before data collection, and workshop training for members of the field teams was conducted in each of Saudi Arabia's 13 regions. Data collection was made by house-to-house visits and completed over 2 years (2004 and 2005). The survey questionnaire, clinical examination, and body measurements (length, height, weight, and head circumference) were completed by primary care physicians and nurses. BMI was also calculated. Intraobserver and interobserver variations were assessed once for every 100 measurements. The precise age at the time of measurement was calculated based on the exact date of birth available in the Saudi family card (an official document that provides the name and birth date of each child in the household).

\section{Statistical Analysis}

The lambda, mu, and sigma statistical methods were used to construct and smooth the growth charts. ${ }^{13-15}$ SD scores were used to compare growth patterns between boys and girls. Lmsqreg models for girls were used to standardize the data of each growth parameter, and the appropriate regression models were fitted separately for girls and for boys. As a result of this standardization, the regression line for girls was zero. Accordingly, if there was no difference between boys and girls, the regression line for boys was also zero. However, if there were differences, they would be indicated by a nonzero regression line that would be higher or lower than the regression line for girls, characterizing the 
variation in growth parameters between boys and girls and expressed in the $z$ score. The significance of the difference between the 2 lines for any growth parameter was tested by ANCOVA. A $P$ value $<0.05$ was considered significant. Finally, selected percentiles (5th, 50th, and 95th) for weight-for-age and height-for-age for boys and girls 2 to 19 years of age were superimposed to assess patterns of growth differences.

\section{RESULTS}

A total of 35,279 healthy children and adolescents from birth to 19 years of age satisfied the criteria for growth measurements. There were 17,880 boys and 17,399 girls; all were Saudi nationals. Figure 1 shows the pattern of variation in the main growth parameters in children from birth to 3 years of age, with $z$ scores for all measurements (weight, height, BMI, and head circumference) higher for boys than for girls (zero line). Based on the pattern of sex differences in the group aged 2 to 19 years depicted in Figure 2, there was an initial phase of higher $z$ scores for boys (ie, higher growth than girls). This was followed by a period of negative $z$ scores for boys starting between 7 and 8 years of age for weight, height, and BMI, and between 10 and 11 years for head circumference. This period of higher growth parameters for girls ended at $\sim 11$ years for height, 14.5 years for weight and head circumference, and continued through 19 years for BMI, when $z$ scores crossed the zero line and became increasingly positive, indicating higher growth for boys.

Figure 3 and Figure 4 show superimposed selected percentiles (5th, 50th, and 95th) for weightfor-age and height-for-age, respectively, for subjects aged 2 to 19 years. Comparison of the weightfor-age percentiles between boys and girls indicated consistently slower growth in girls affecting the 5th, 50th, and 95th percentiles (up until 7, 6, and 5 years of age, respectively). This was followed by a period of overlap, then a brief period of upward shift of the percentiles for girls more marked in the 5th and 50th percentiles between 10 and 14 years

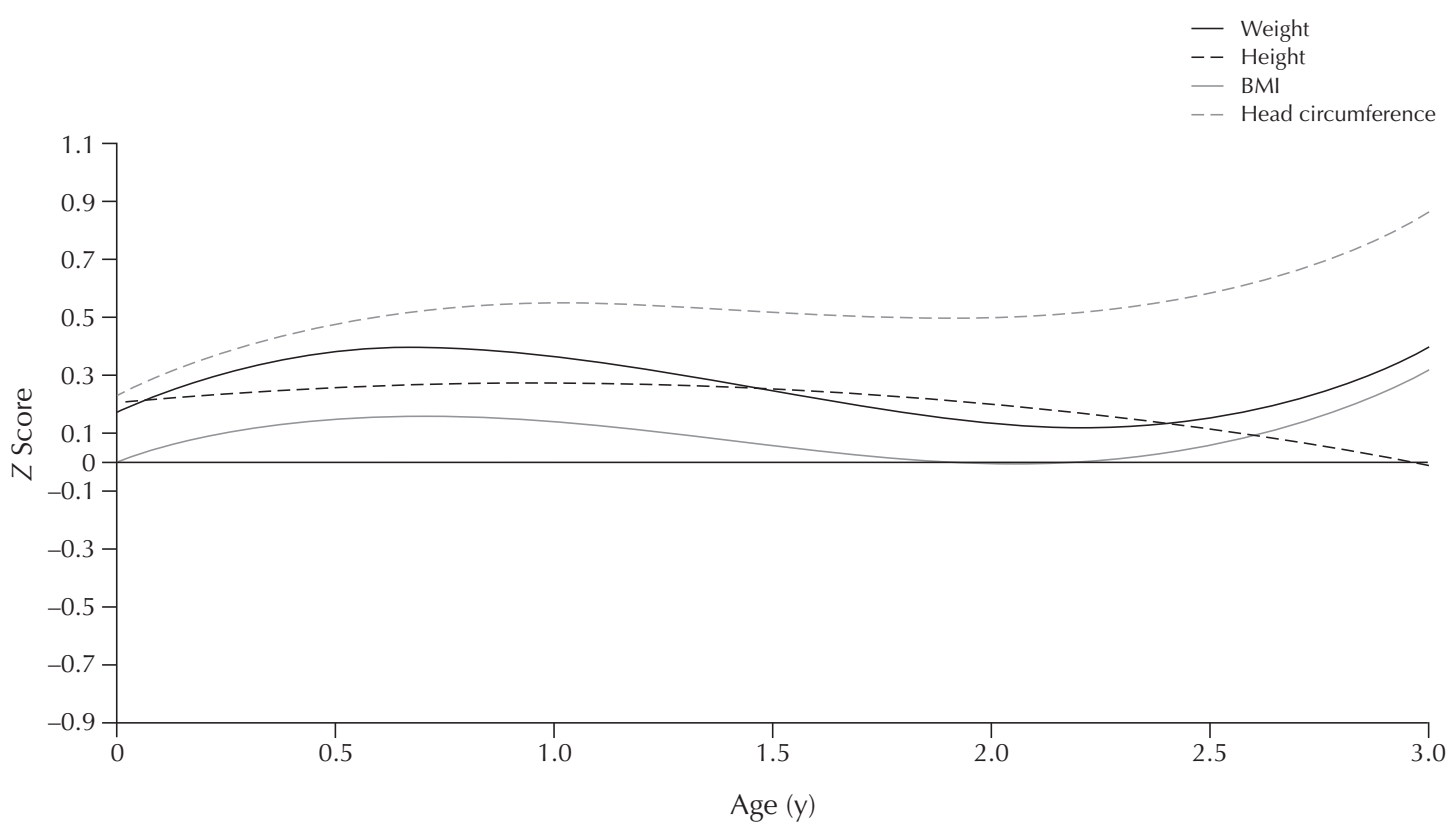

Figure 1. Sex differences (based on z scores) in weight, height, body mass index (BMI), and head circumference for subjects aged birth to 3 years. As a result of standardization of the data for each growth parameter, the regression line for girls was zero. 


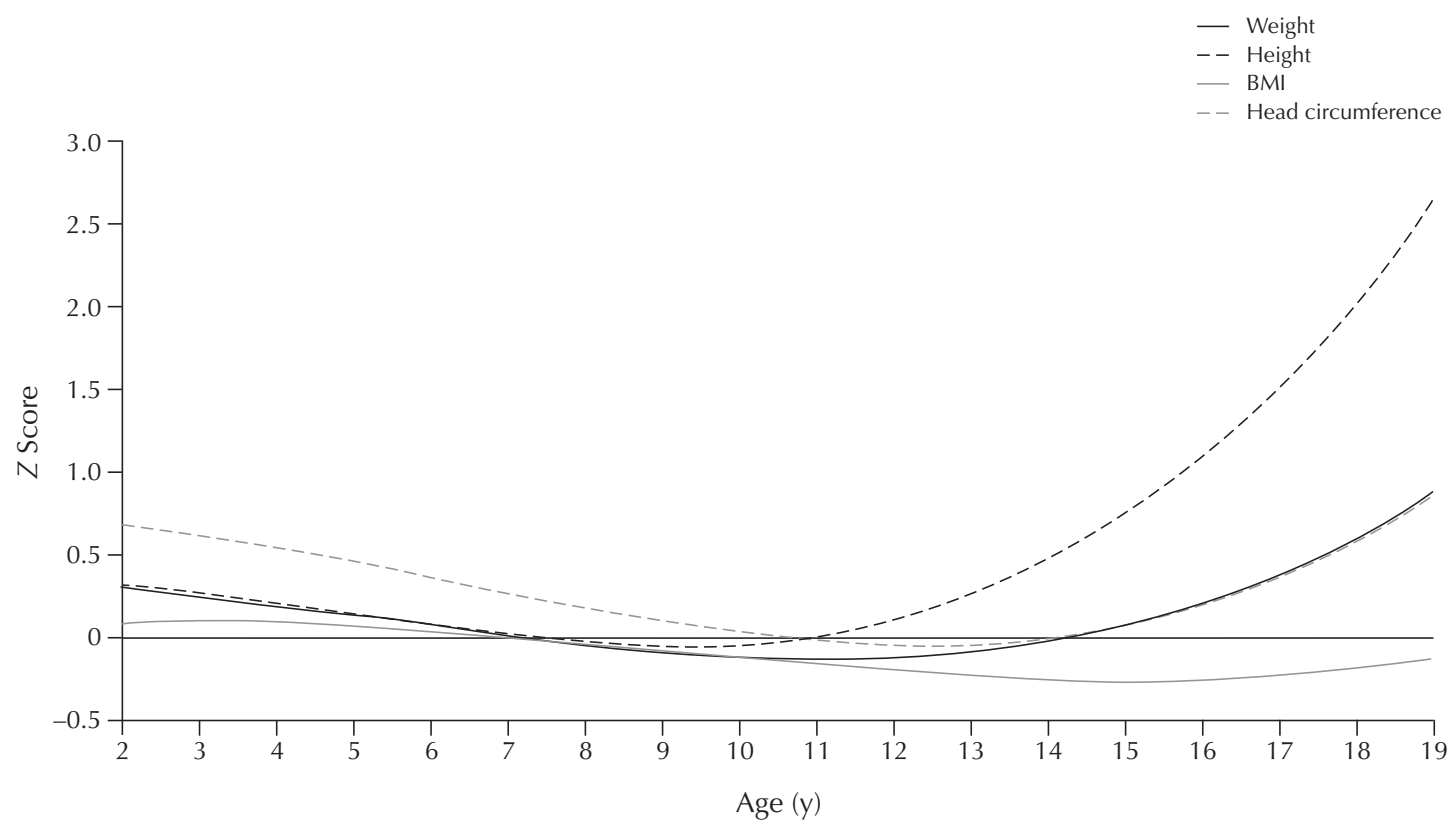

Figure 2. Sex differences (based on z scores) in weight, height, body mass index (BMI), and head circumference for subjects aged 2 to 19 years. As a result of standardization of the data for each growth parameter, the regression line for girls was zero.

of age (Figure 3). This was followed by a sharp drop of the weight percentile starting between 14 and 16 years of age, with an increasing gap in weight-forage between boys and girls. Similarly, the pattern of gender variation in height-for-age percentiles showed a generally slow growth for girls, followed by a period of overlap, then a period of upward shift of height for girls more marked in the 5th and the 50th percentiles (up until 13.5 and 12 years, respectively) (Figure 4). A sharp downward shift in height for girls, similar to that for weight, occurred between 13 and 14 years of age and continued through 19 years of age. The difference between boys and girls for each growth parameter was highly significant $(P<0.001)$.

\section{DISCUSSION}

It has been documented that the growth of children, as assessed using anthropometric measurements, is affected by a combination of genetic and environmental factors. Although studies suggest a minimal role of genetic factors, ${ }^{16-18}$ ethnic variations both between individuals and populations cannot be excluded. ${ }^{19}$
Differences in growth between boys and girls are well known and have been reported in most studies on the subject, leading to the development of separate growth charts for boys and girls. ${ }^{2,4,5}$ However, no detailed description of the pattern and significance of variation has been reported in representative samples of any population. Previous studies from Saudi Arabia reported gender variations in a particular age group or a single region, and therefore the samples were not representative of the general population. In a study on the growth of preschool Saudi children in Riyadh, Al-Frayh et $\mathrm{al}^{9}$ reported that boys were slightly taller than girls during the first year of age; thereafter, girls tended to be taller, and only slight differences in weight were observed in favor of boys. Such patterns differ from results of the present study, in which boys were consistently taller and heavier than girls from birth to 3 years of age. Two other studies including older children have been reported from Saudi Arabia. One study was by Attallah ${ }^{20}$ and included children and adolescents of military dependents from birth to 19 years of age from the Asir region 


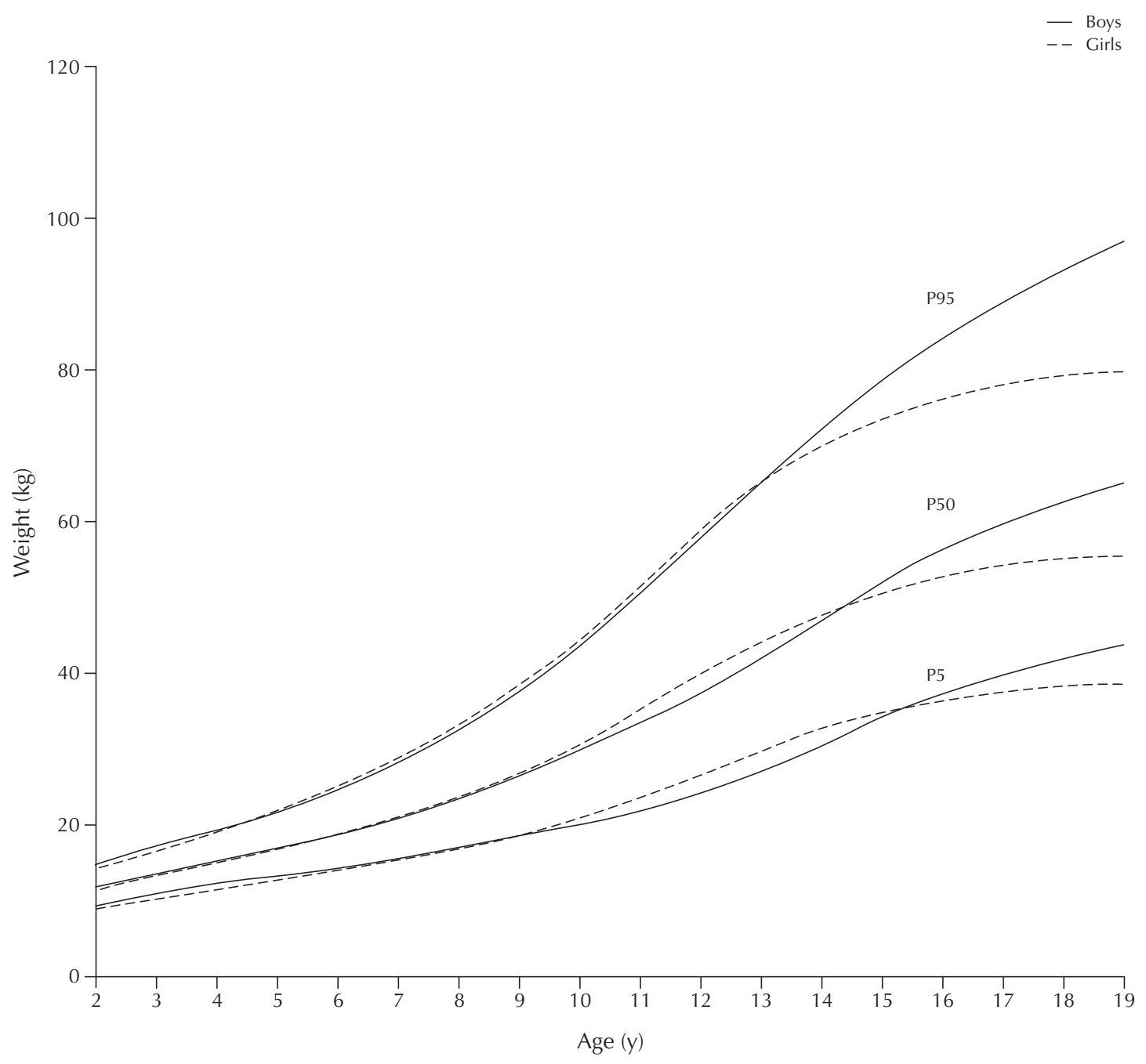

Figure 3. Sex differences in weight-for-age percentiles (P) (5th, 50th, and 95th) for subjects aged 2 to 19 years.

of Saudi Arabia. Sex differences were found for weight, length, and height, indicating that boys were both taller and heavier than girls in general up to 12 to 13 years of age, at which point girls became taller than boys. After the age of 13 years, however, boys were taller and heavier than girls. In a national study of school-aged children aged 6 to 18 years, Al-Sekait et $\mathrm{al}^{8}$ reported that boys were generally heavier and taller. However, girls became heavier after age 10 years and taller at 12 to 13 years of age. Finally, in a national survey of Saudi preschool children, Al-Amoud et al $^{21}$ reported that boys were taller and heavier than girls. Similar findings regarding gender variations have been reported from other developing countries such as Nigeria, ${ }^{22}$ Egypt, ${ }^{23}$ and India. ${ }^{24}$

A relatively more detailed description of sex differences has been reported in the Euro-Growth reference for children from birth to 3 years, indicating significantly larger mean values for boys' length $(P=0.001-0.005)$, weight $(P=0.001-0.003)$, and head circumference $(P=0.001) .{ }^{4}$ This pattern is consistent with our results. The 2006 WHO standards, ${ }^{5}$ which are based on a selected multina- 


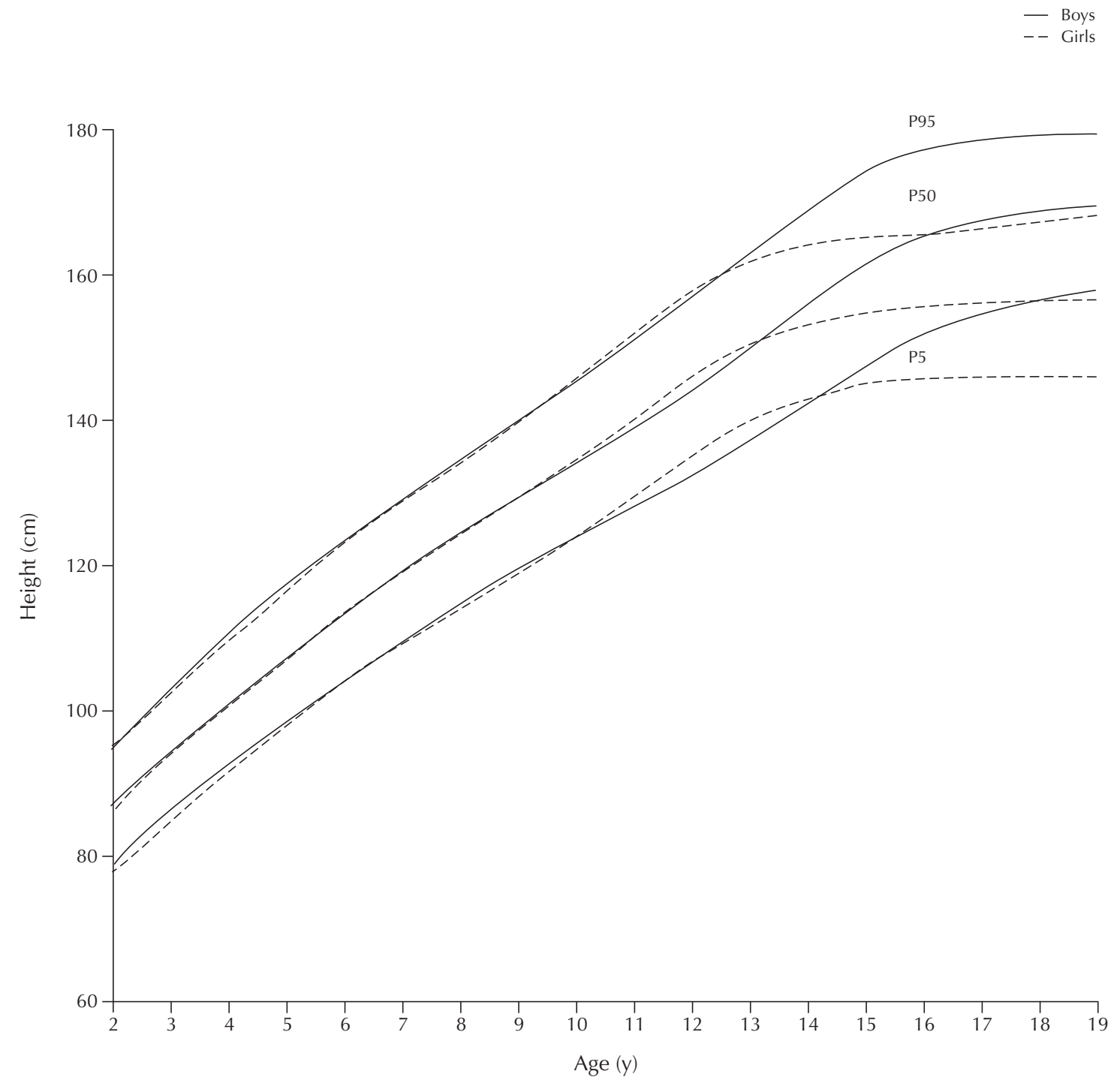

Figure 4. Sex differences in height-for-age percentiles (P) (5th, 50th, and 95th) for subjects aged 2 to 19 years.

tional sample of subjects aged birth to 60 months, presented sex differences in the form of superimposed $z$-score curves for length/height-for-age, weight-for-age, weight-for-length, and BMI-forage, indicating generally higher scores for boys across all age groups; this pattern is similar to the Euro-Growth reference ${ }^{4}$ and the present findings. However, no calculation of the significance level was provided in the WHO guidelines. ${ }^{5}$ The more recent 2007 WHO publication, which is a reanaly- sis of the $1977 \mathrm{NCHS} / \mathrm{WHO}$ growth reference data set for children and adolescents 5 to 19 years of age, presented a tabulation of the median and $Z$ scores for weight-for-age, height-for-age, and BMI-for-age using state-of-the-art statistics; the results indicated higher values for boys. ${ }^{6}$ These patterns are similar to those described in the present study. However, because of the statistical approach we used, which provides a more accurate impression of the difference across all age groups rather 
than the classic sum in the form of a mean or median, quantitative comparison with the 2006 WHO standards or the 2007 WHO reference is difficult.

The present report, based on a representative sample of healthy Saudi children and adolescents randomly selected from each region of the country covering all age groups from birth to 19 years, provides a detailed description of the pattern of sex differences in the growth of children and adolescents. The 2 methods of presentation of our results give an accurate description of sex differences for each growth parameter according to age. The finding from our study that Saudi boys up to $\sim 7$ years of age were generally taller and heavier than girls confirms results from previous studies. $2,4,5$ Girls became taller and heavier than boys between 7 and $\sim 15$ years of age; boys were then taller and heavier after this period. It appears that the earlier maturation of girls explains the findings that they become heavier and taller than boys but only until boys start to mature, at which time the pattern is then reversed in favor of boys. Although this pattern has been linked most commonly to differences in the timing of maturation between boys and girls, other issues-such as hormonal patterns, physical activity, and social factors-have been reported to affect the growth of boys and girls differently. ${ }^{25,26}$

Based on our study results and results from the literature, 3 phases in the pattern of gender variation in growth can be identified. The first phase is from birth to the beginning of maturation of girls at $\sim 10$ years, when all growth parameters of boys are higher than girls. The second phase is characterized by crossing of the girls' growth curves over those of the boys, leading to a period of higher growth parameters for girls that continues until the beginning of maturation of boys at $\sim 14$ years of age. The third phase then begins, when the boys' growth curves cross over those of the girls, representing the boys' higher growth. These variations were remarkably consistent not only across all growth parameters but also among countries. $2,4,5$ The highly significant difference in the pattern of growth between boys and girls provides an explanation for the practice of separate growth charts.

\section{CONCLUSIONS}

Based on analysis of these Saudi children and adolescents, the difference in growth between boys and girls was not uniform but depended on age. However, the pattern was remarkably consistent across all growth parameters and appears to reflect the timing of maturation between boys and girls.

\section{ACKNOWLEDGMENTS}

This study was supported by a research grant from King Abdul Aziz City for Science and Technology (Riyadh, Saudi Arabia) (grant no. AR-20-63). The authors have indicated that they have no other conflicts of interest regarding the content of this article.

\section{REFERENCES}

1. Hamill PV, Drizd TA, Johnson CL, et al. Physical growth: National Center for Health Statistics percentiles. Am J Clin Nutr. 1979;32:607-629.

2. Kuczmarski RJ, Ogden CL, Guo SS, et al. 2000 CDC Growth Charts for the United States: Methods and development. Vital Health Stat 11. 2002:1-190.

3. Freeman JV, Cole TJ, Chinn S, et al. Cross sectional stature and weight reference curves for the UK, 1990. Arch Dis Child. 1995;73:17-24.

4. Euro-Growth Study Group. Euro-Growth references for length, weight, and body conferences. Huschke F and Van't Hof ME, eds. J Pediatr Gastroenterol Nutr. 2000;31(Suppl 1):S14-S38.

5. WHO Multicentre Growth Reference Study Group, WHO Child Growth Standards. Length/Height-forAge, Weight-for-Age, Weight-for-Length, Weightfor-Height and Body Mass Index-for-Age: Methods and Development. Geneva, Switzerland: World Health Organization; 2006.

6. de Onis M, Onyango AW, Borghi E, et al. Development of a WHO growth reference for school-aged children and adolescents. Bull World Health Organ. 2007;85:660-667.

7. al-Mazrou Y, al-Amood MM, Khoja T, et al. Standardized national growth chart of $0-5$-yearold Saudi children. J Trop Pediatr. 2000;46:212-218.

8. Al-Sekait MA, Al-Nasser AN, Bamgboye EA. The growth pattern of schoolchildren in Saudi Arabia. Saudi Med J. 1992;13:141-146. 
9. Al-Frayh AS, Bamgboye EA, Moussa MA. The standard physical growth chart for Saudi Arabian preschool children. Ann Saudi Med. 1993;13:155-159.

10. al-Nuaim AR, Bamgboye EA, al-Herbish A. The pattern of growth and obesity in Saudi Arabian male school children. Int J Obes Relat Metab Disord. 1996;20:1000-1005.

11. El Mouzan MI, Al Herbish AS, AI Salloum AA, et al. The growth charts for Saudi children and adolescents. Saudi Med J. 2007;28:477-490.

12. Waterlow JC, Buzina R, Keller W, et al. The presentation and use of height and weight data for comparing the nutritional status of groups of children under the age of 10 years. Bull World Health Organ. 1977;55:489-498.

13. Cole TJ, Green PJ. Smoothing reference centile curves: The LMS method and penalized likelihood. Stat Med. 1992;11:1305-1319.

14. Cole TJ, Freeman JV, Preece MA. British 1990 growth reference centiles for weight, height, body mass index and head circumference fitted by maximum penalized likelihood. Stat Med. 1998;17: 407-429.

15. Rigby RA, Stasinopoulos DM. Generalized additive models for location, scale and shape. Applied Statistics. 2005;64:507-554.

16. Habicht JP, Martorell R, Yarbrough C, et al. Height and weight standards for preschool children. How relevant are ethnic differences in growth potential? Lancet. 1974;1:611-614.

17. Graitcer PL, Gentry EM. Measuring children: One reference for all. Lancet. 1981;2:297-299.
18. WHO Multicentre Growth Reference Study Group. Assessment of differences in linear growth among populations in the WHO Multicentre Growth Reference Study. Acta Paediatr Suppl. 2006;450:5665.

19. WHO Working Group. Use and interpretation of anthropometric indicators of nutritional status. Bull World Health Organ. 1986;64:929-941.

20. Attallah NL. Patterns of growth of Saudi boys and girls from birth up to maturity in the Asir region before the turn of the twentieth century. Saudi Med J. 1994;15:414-423.

21. Al-Amoud MM, Al-Mazrou YY, El-Gizouli SE, et al. Clinical growth charts for pre-school children. Saudi Med J. 2004;25:1679-1682.

22. Janes MD. Physical growth of Nigerian Yoruba children. Trop Geogr Med. 1974;26:389-398.

23. Aly HE, Moussa WA, Demian HG, et al. Anthropometric measurements of Cairo schoolchildren. A follow up study. J Egypt Publ HIth Assoc. 1980; 3:143-165.

24. Khan AZ, Singh NI, Hasan SB, et al. Anthropometric measurements in rural school children. $J R$ Soc Health. 1990;110:184-186.

25. Engström BE, Karlsson FA, Wide L. Marked gender differences in ambulatory morning growth hormone values in young adults. Clin Chem. 1998;44: 1289-1295.

26. Jones G, Dwyer T. Bone mass in prepubertal children: Gender differences and the role of physical activity and sunlight exposure. J Clin Endocrinol Metab. 1998;83:4274-4279.

Address correspondence to: Mohammad I. El Mouzan, MD, Department of Pediatrics, King Saud University, PO Box 2925, Riyadh 11461, Saudi Arabia. E-mail: drmouzan@gmail.com 